\title{
Uma perspectiva racionalista da influência do Estado na pandemia
}

Lorraine Fatima Bim SilvaI (100000-0002-5412-571X

Universidade de Taubaté, Taubaté, São Paulo, Brasil

Resumo: A compreensão deste texto ocorre a partir de duas diferentes perspectivas: (1) psicológica, entendendo o conceito de racionalismo como a superioridade da razão sobre outras áreas da vida humana; (2) política, em que a ideia de racionalismo é compreendida a partir, principalmente, de pressupostos do filósofo inglês Michael Oakeshott.

Palavras-Chave: Racionalismo, Psicologia, Escola Austríaca, Pandemia.

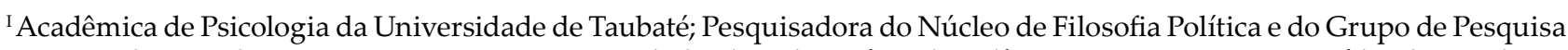
A Crise do Amadurecimento na Contemporaneidade, do Laboratório de Política, Comportamento e Mídia da Fundação São Paulo /PUC-SP - LABÔ. E-mail: lorrainebim@hotmail.com
} 


\title{
Una perspectiva racionalista de la influencia del Estado durante la pandemia
}

Resúmen: La comprensión de este texto se da a partir de dos diferentes perspectivas: (1) psicológica, entendiendo el concepto de racionalismo como la superioridad de la razón sobre otras áreas de la vida humana; (2) política, en que la idea de racionalismo es comprendida a partir, principalmente, de presupuestos del filósofo inglés Michael Oakeshott.

Palabras clave: Racionalismo, Psicología, Escola Austríaca, Pandemia.

\section{A rationalist perspective on the State's influence in the pandemic}

\begin{abstract}
To understand this text, we need to explore two different perspectives: (1) psychological, understanding the concept of rationalism as the superiority of reason over other areas of human life; (2) political, in which we understand the idea of rationalism based on the assumptions of the English philosopher Michael Oakeshott.
\end{abstract}

Keywords: Rationalism, Psychology, Austrian School, Pandemic. 


\section{Introdução}

Ao se considerar os impactos de uma pandemia em uma sociedade, é compreensível que, de maneira geral, as pessoas se sintam apreensivas e desejem que decisões seguras sejam tomadas para que elas sejam protegidas. O problema aparece quando, sem perceber, abre-se espaço para que terceiros arroguem para si o direito de decidir por todos aquilo que pode ou não ser feito, baseados em uma suposta garantia de segurança. Durante a pandemia do COVID-19, a aparência de certeza de declarações alegadamente científicas parece deixar as populações de diferentes países à vontade para entregar suas liberdades e responsabilidades nas mãos de um ente supostamente a favor delas: o Estado.

Quando discursos, teoricamente, certeiros e corretos sobre medidas de segurança, contingenciamento e previsões passam a pautar as decisões durante uma pandemia, sem abertura para discordâncias e debates - porque isso seria obscurantismo e contra a ciência - as consequências podem ser desastrosas. Partindo de pressupostos racionalistas, governantes ao redor de todo o mundo têm se esforçado para aplicar medidas que só fazem sentido às custas da realidade objetiva. A questão que se levanta é: estamos realmente confiantes que o Estado quer o bem de todos e, por isso, não só é muito mais racional que indivíduos livres, como também sabe melhor que todos a direção que devemos seguir para alcançar a segurança plena?

\section{Racionalismo e subjetividade humana}

A Psicologia, ciência muito utilizada atualmente para compreender, explicar e justificar comportamentos humanos, surgiu de duas grandes tradições: das ciências naturais e da filosofia. Desde que o ser humano pensa, ele pensa sobre si mesmo, sobre os outros e sobre o mundo ao seu redor. Essa característica remete à filosofia grega e acompanha toda a discussão filosófica desde então, até os tempos atuais.

Nesse caminho, Luis Cláudio Figueiredo, em Psicologia: Uma introdução (1979), aponta que a ideia da Psicologia, enquanto ciência, surgiu a partir de duas condições: o surgimento da percepção de uma subjetividade privada - isto é, da noção de seres humanos como indivíduos livres, separados uns dos outros e donos de seus próprios destinos; e uma possível crise dessa concepção de sujeito, que teria gerado a necessidade de um profissional que restituísse a estabilidade dos indivíduos.

No mundo atual, confuso em seus dilemas entre individualismo e coletivismo, pode provocar estranheza pensar no "surgimento" da noção de subjetividade, como se ela não existisse antes. Porém, apesar de encontrar certas características desde a Grécia antiga que remetem ao humanismo - como a valorização do ser humano, a democracia ou a criação do direito -, a ideia de que possuímos uma interioridade parece ter surgido no período do Renascimento, quando o pensamento Racionalista marcou diversas mudanças de paradigmas, atribuindo confiança à razão humana como principal fonte de conhecimento.

Nessa transição da Idade Média para a Idade Moderna, também ocorreu uma mudança na concepção do lugar do homem no mundo, com uma grande valorização do ser humano, ao 
mesmo tempo em que surge a ideia de que ele deve também se constituir enquanto humano, já que a ideia de liberdade veio acompanhada de solidão e responsabilidade. Se até então, o homem se apoiava em referencias externa e contava com uma autoridade absoluta, a partir desse momento, ele deverá construir suas próprias respostas.

A ideia racionalista se baseia na busca da certeza, considerando um tipo de conhecimento que surge de modo direto da razão. Descartes, filósofo, físico, matemático francês, considerado o pai fundador da filosofia moderna e do Racionalismo Cartesiano, se propôs a refletir sobre as coisas do mundo, com o intuito de saber se elas podiam fornecer uma verdade segura e, uma vez firmado um ponto de referência, o restante viria por dedução, afirmando que é preciso duvidar de todo saber adquirido para conseguir alcançar a razão absoluta.

Sua famosa frase, "cogito, ergo sum" ("penso, logo existo"), vem de sua conclusão de que, depois de ter duvidado de todas as coisas e ter tomado todo objeto de seu pensamento como incerto, a atividade de duvidar lhe parecia indubitável. Ou seja, o único ponto de referência alcançado é que temos um "eu" - não como corpo, porque isso também foi questionado - que funciona como uma alma racional, um eu pensante. Uma noção importante que surge daí é a ideia de que a consciência, o pensamento, tem mais certeza do que a matéria, o corpo.

Portanto, de Descartes em diante, um conhecimento só seria considerado verdadeiro ao passar pelos crivos da razão humana e de seu "eu pensante". Nesse sentido, a estabilidade do mundo passou a depender da identidade do eu e por isso, qualquer situação, evento ou circunstância que desestabilizasse a lucidez desse eu, poderia ser vista como uma ameaça.

\section{O racionalismo na política}

Michael Oakeshott, teórico político inglês, tem sua obra marcada por uma profunda crítica ao racionalismo, especialmente ao racionalismo político. Em Rationalism in Politics (1962), o autor afirma que a política da Europa pós-renascentista estava infectada pelo racionalismo e contrapõe duas ideias: o conhecimento prático e o conhecimento técnico.

O primeiro se refere ao saber que existe somente a partir da prática humana. É um conhecimento vindo da tradição e do hábito, que não pode ser ensinado em métodos teóricos, mas apenas adquirido através da experiência e de um constante contato com alguém que possui tal conhecimento. Esse saber envolve o domínio de certas habilidades e, normalmente, aparenta ser impreciso, porque ocorre, justamente, na prática.

Já o segundo se refere a um saber possível de ser colocado em regras ou fórmulas, podendo ser organizado de modo estruturado e ensinado mecanicamente, o que, talvez, faça com que o conhecimento técnico tenha uma aparência de certeza, completude e autossuficiência. Uma política racionalista é baseada neste tipo de conhecimento, priorizando a razão em detrimento da experiência, exaurindo a ideia de que a soberania da razão é a soberania da técnica.

A crítica de Oakeshott se dá em relação ao fato de que toda atividade humana, desde a ciência até a arte, envolve os dois tipos de conhecimento. Para ele, tanto a teoria, quanto a prática são complementares e interdependentes, e o erro racionalista seria desconsiderar a experiência humana acumulada ao longo da história, tendo como certo e autocompleto 
apenas o conhecimento técnico. Ou seja, apesar do racionalismo apresentar a técnica como o conhecimento único, ela está colocada em um contexto muito mais amplo, que é o conjunto de práticas humanas ao longo dos séculos.

Fato é que a realidade concreta é imprecisa, incerta e imprevisível. Teorizar a respeito dessa realidade somente é possível a partir do passado ou a partir de possibilidades - que nem sempre se concretizam. Exemplo disso são as possibilidades levantadas por Thomas Hobbes, filósofo, teórico político e matemático inglês contemporâneo de Descartes, a respeito da natureza humana.

Hobbes (1979) defende que o homem deve seguir o caminho da racionalidade e aponta para uma racionalização dos mecanismos do poder e de instituição do Estado. Ele acreditava que, na ausência de um poder absoluto e sem compromissos entre as pessoas que estabelecessem o que pertence a cada um, o ser humano teria o direito de fazer o que quisesse, buscando sempre o que é bom para si próprio e evitando o que é mau.

A questão chave é que a busca pelo que é bom, sem uma referência externa e com uma gradual importância dada ao eu, se refere justamente a uma busca pelo bem para si, e não a busca de um bem comum. Considerando que, para Hobbes, a natureza humana é egoísta e movida pelo prazer, frequentemente, o homem seria levado à violência e o resultado seria uma eterna guerra de todos contra todos. Paradoxalmente, o princípio de autoconservação do homem é conduzido pelo medo da morte nessa possível guerra.

Desse modo, os homens no estado de natureza são permeados por uma desconfiança mútua, sentindo-se ameaçados e, por isso, possuindo o desejo de se ferirem. Para Hobbes, é a pobre condição do ser humano estar sozinho na luta pela vida, podendo ser prejudicado a qualquer instante por qualquer um a sua volta. Para se libertar de tal condição instaura-se um tempo de guerra:

Portanto tudo aquilo que é válido para um tempo de guerra, em que todo homem é inimigo de todo homem, o mesmo é válido para o tempo durante o qual os homens vivem sem outra segurança senão a que lhes pode ser oferecida por sua própria força e sua própria invenção. Numa tal situação não há [...] sociedade; e o que é pior do que tudo, um constante temor e perigo de morte violenta. E a vida do homem é solitária; pobre sórdida, embrutecida e curta. (HOBBES,1979, p.76)

Hobbes atribuiu um sentido metafórico ao conceito de guerra, como sendo uma disposição a se preocupar constantemente com a sobrevivência diante da ameaça de morte violenta que caracteriza a vida de maneira "pobre, sórdida, embrutecida e curta". A guerra seria a constante sensação de medo e, portanto, uma permanente preocupação com a autopreservação.

A partir disso, o autor conclui que é racional procurar a paz sempre que possível e, caso contrário, é necessário se preparar para a guerra. Ele defende que, para alcançar a paz, os homens precisam transferir seus direitos e uma das maneiras de fazer isso seria a formação de acordos entre indivíduos. Entretanto, este modo não garantiria uma paz generalizada, fazendo-se necessária a constituição de um Estado civil, tendo como limite nesse contrato a preservação do direito à sobrevivência e a proteção de seu corpo. 
Entende-se, então que, para o pensamento hobbesiano, a ordem política não surge somente da impotência humana, mas também da capacidade de racionalizar que leva o ser humano a criar a possibilidade de corrigir e aperfeiçoar a natureza humana. A instituição política se torna o artifício humano capaz de tornar eficaz a ideia de poder absoluto. Surge daí o modelo de Estado máximo de Hobbes, como uma resposta à questão da natureza humana, propondo que não há ordem sem soberania. Soberania esta que pertence ao todo coletivo, cuja unidade exige a mediação e a representação. Dessa forma, a figura do Estado é fundamental para a teoria hobbesiana na medida em que garante o equilíbrio entre o caos do homem e sua necessidade de permanecer em grupo.

Essa concepção de Estado como poder supremo sobre o ser humano, é baseada em uma racionalização acentuada do medo sobre o que as pessoas podem ou não fazer quando deixadas sem supervisão. Se trata de uma proposta de ação para limitar o ser humano de agir de maneira prejudicial em relação a si mesmo e aos outros, mas para isso, cria-se a figura de um Estado como mediador do medo dos indivíduos e como uma entidade capaz e satisfazer a necessidade humana de proteção.

\section{O Estado em tempos difíceis}

Paradoxalmente, uma polêmica frase dita por Carl Von Clausewitz militar prussiano, ficou conhecida como uma definição de guerra: "a guerra é a continuação da política por outros meios" (2010, p. 30). Para ele, há uma "trindade" envolvida nas guerras, que seria a violência, o ódio e animosidade, e é possível entender a natureza da guerra como subordinada à política, através da qual ela pertence à razão pura.

Desde o mundo antigo, impérios dominavam territórios, reis soberanos dominavam a vida política e diversos sistemas de organização social foram se baseando na dominação, no roubo e na guerra. Em determinado momento histórico, a identificação da sociedade com o Estado aumentou e, como apontado por Murray Rothbard, economista que estabeleceu a Escola Austríaca e a doutrina liberal clássica nos EUA, é comum que se ouça apelos sentimentais de "nós somos o governo". Entretanto, essa percepção coletiva de Estado gera uma "camuflagem ideológica" sobre a realidade política, em que qualquer ação do governo sobre um indivíduo é entendida como voluntária por parte do indivíduo mesmo, considerando que ele compõe o governo.

No livro A Anatomia do Estado (2019), Rothbard explica o ponto de equívoco desta ideia citando duas possíveis interrelações humanas básicas mutuamente exclusivas para obtenção de riqueza: o meio econômico (que seria uma troca em cooperação pacífica) e o meio político (que seria a exploração coerciva feita pelo Estado). Para ele, a história humana pode ser entendida a partir de uma disputa entre estes dois princípios e, a partir dessa distinção, ele define o Estado como a "sistematização do processo predatório sobre um determinado território", funcionando não como um contrato social, mas sendo gerado a partir da conquista e da exploração.

Com isso, entende-se que a existência do Estado não garante a ausência de guerras ou de violência. Apenas aponta para outros objetivos. Diferente do que, talvez, foi proposto por 
Hobbes, os intitulados "homens públicos" agem segundo seus próprios interesses e não a procura de um bem comum. Inegável é que, em uma guerra, o poder do Estado é levado ao extremo, e não o contrário. Alegando defender, assegurar e proteger seus cidadãos, o Estado pode impor uma tirania que, em tempos normais, enfrentaria intensa resistência. Momentos de crise são perfeitos para que seja exigido obediência a todo decreto emergencial ou protocolo de segurança, sem garantia de retomada à normalidade em algum futuro próximo.

Retomando a obra de Michael Oakeshott (2018), outra diferenciação conceitual feita por ele foi entre a "política do ceticismo" e a "política da fé", dois extremos abstratos, cuja região intermediária é ocupada por nossa compreensão de governo que, esporadicamente, se aproxima dos polos.

A política do ceticismo parte da ideia de que não devemos concentrar nossos esforços na perfeição humana, porque sabemos muito pouco a respeito dela ou pelo fato de que é uma ilusão. É um estilo de governar fundamentado em uma desconfiança cautelosa e em uma leitura da conduta humana, não de sua natureza. Nesse sentido, o governo "subsiste não porque é bom, mas porque é necessário" (p. 69) e sua única preocupação é o efeito da conduta na ordem pública.

Já a política da fé tem a arte de governar a serviço de uma utópica perfeição da humanidade, e essa busca se dá não pela observação de uma experiência prática, mas pelo esforço humano em que o governo é o principal agente do aprimoramento que resultará na perfeição. Para alcançar o ideal de humanidade, a função do governo envolve o controle e organização da atividade humana. Como dito por Oakeshott, "é típico dessa política acolher o poder em vez de sentir-se constrangido por ele; nenhuma quantidade de poder jamais será considerada excessiva" (p. 65).

Em situações em que a sociedade aparenta estar ameaçada e que a proteção parece mais importante do que qualquer outra atividade, tendemos a acreditar em uma importância superior da atividade política em detrimento de todas as outras. Mas, segundo Oakeshott, isso é uma tentação a ser evitada, porque a proteção usurpa o lugar da recreação apenas na ausência ou na pobreza de uma atividade criativa. Ou seja, mesmo que ocasionalmente uma sociedade possa sobreviver através da ação política, viver de fato requer uma atividade social diferente, envolvendo a criatividade individual muitas vezes ameaçada pelo sucesso ou fracasso político.

A questão que surge é: em tempos incomuns, estaremos dispostos a entregar nossa liberdade, permitindo que o Estado controle nossas atividades, na busca por um ideal inalcançável, correndo-se o risco de ser estabelecido um permanente legado de maiores encargos estatais sobre a sociedade?

\section{Pandemia, Estado e Racionalismo}

Trazendo aos termos atuais, o Estado acaba se tornando fonte de mais incertezas do que as que já existem naturalmente na realidade humana. Em 2020, com a pandemia do COVID-19, temos convivido com grandes instabilidades e as inseguranças jurídicas, políticas e sociais no país tem trazido ainda mais incertezas à tona. 
O ex-presidente do Brasil, Luiz Inácio Lula da Silva, disse recentemente que o novo coronavírus teria sido algo positivo, já que nessa circunstância, as pessoas estavam voltando a perceber que "apenas o Estado é capaz de dar solução a determinadas crises” (SOUZA, 2020).

Entretanto, como sempre, o que a realidade mostra é diferente da teoria. Todas essas modificações foram realizadas em função de pressupostos científicos a respeito de um vírus relativamente novo e muito desconhecido. Utilizando o conceito de racionalismo político de Oakeshott, chegamos a um período de uso cada vez mais comum de noções abstratas que fazem sentido apenas se for à custa da realidade concreta. Os diversos racionalistas que podemos encontrar no contexto atual, tanto no Brasil quanto em outros países, não percebem as diferenças que existem entre uma ideia no papel e seu efeito na realidade.

Os debates estritamente técnicos atuais, principalmente em relação às medidas de contingenciamento contra a pandemia, apontam para o caráter Racionalista presente na sociedade contemporânea, em que os conselhos de especialistas ou de autoridades políticas são seguidos rigorosamente, como verdades absolutas, em busca de orientação e liderança.

As discussões cientificas nunca estão concluídas, especialmente quando se trata de um tema novo. O que muitos especialistas têm alegado como fatos científicos são na verdade pseudo-estudos, estabelecidos em um contexto em que os próprios cientistas fazem declarações conflitantes e divergem entre si, em uma busca desenfreada por afirmar com maior certeza qual deve ser o próximo passo.

Apesar disso, por todo o mundo, governos decidiram intervir nas questões econômicas e sociais de seus países, ordenando que empresas de "serviços não-essenciais" permanecessem fechadas, que viagens fossem impedidas, que determinadas transações fossem proibidas e que pessoas ficassem em casa - em algumas cidades do Brasil, por exemplo, corria-se o risco de serem multadas e até presas, caso saíssem indevidamente.

Paradoxalmente, certos estabelecimentos considerados essenciais - lembrando que o próprio governo decidiu quais empresas se classificam dessa forma ou não - permaneceram funcionando, com diversas aglomerações em lugares fechados, como supermercados. É provável que algumas medidas piorem a doença. $\mathrm{O}$ isolamento no verão e a impossibilidade de sair para lugares abertos e com ar fresco podem reduzir a imunidade das pessoas. Idosos e pessoas do grupo de risco foram obrigadas a ficarem confinadas em casa, onde o risco de que haja uma redução de vitamina $\mathrm{D}$, essencial para a imunidade, é maior. Em questão de dias, toda a ordem de funcionamento mundial foi alterada.

Defensores de ambos os lados políticos afirmaram categoricamente que suas propostas e medidas de segurança eram as mais eficazes na contenção da pandemia. Sem nenhuma organização ou plano de retorno da economia, governos ordenaram quarentenas, lockdowns, isolamento social, uso de máscara e entre tantos outros protocolos. O pânico gerado nesse contexto, além da insegurança social que já existia em países como o Brasil, provavelmente dificultará ainda mais um retorno às atividades mais complexas.

Sem circulação de pessoas, ainda que a economia reabrisse de maneira relativamente rápida, as empresas vivenciaram um colapso de suas receitas, o número do desemprego 
aumentou e é bem provável que o caos social também aumentará. A produção econômica cai, porque a produção de cada indivíduo e empresa também cai.

Como apontado por Rothbard (2019, p. 17), "tendo usado a força e a violência para obter sua receita, o Estado geralmente passa a regular e ditar outras ações de seus súditos individuais". Ou seja, não basta ao Estado depender da renda produzida pela esfera privada, ele também decide como ou quando esta renda será produzida em tempos de crise. E em 2020, é possível perceber que os governos estão dispostos a regular as relações econômicas de empresas que dificilmente conseguirão recursos para se manter funcionando. São questões inaceitáveis que têm causado desastres não somente econômicos, mas no próprio espírito humano.

Além disso, um ponto crucial pode estar sendo deixado de lado com a intervenção atual dos Estados na economia: a possível destruição da divisão internacional do trabalho. Como apontado por Adam Smith, o aprofundamento da divisão do trabalho é fundamental para uma economia consiga se desenvolver, além de permitir o avanço da própria sociedade civilizada. Cada função exercida em diferentes âmbitos só é possível porque há a oportunidade dos indivíduos se especializarem. Ou seja, o avanço do desenvolvimento social e econômico é mútuo e interdependente: "o desenvolvimento do mercado permite uma divisão mais ampla do trabalho; o isso, por sua vez, possibilita uma maior ampliação do mercado" (TORRES, 2020). No contexto atual, essa formação conquistada ao longo dos anos está sendo ameaçada.

Essas limitações das liberdades individuais, supostamente para nosso próprio bem, têm causado mais destruição ainda e impossibilitado que enxerguemos o que de fato nos mantém seguros, em nossos próprios termos, quando nos sentimos ameaçados. Se uma pandemia viral, por si só, já é capaz de impactar significativamente a sociedade, as tentativas políticas de superar a natureza ou de garantir certezas em um cenário imprevisível, afastam ainda mais a sociedade de uma solução. Os efeitos econômicos ainda são desconhecidos, porque serão sentidos, inclusive a longo prazo. Os efeitos emocionais de meses em quarentena também não podem ser vistos no momento. Ainda há muito o que saber e parte do que não sabemos é justamente porque ainda temos sido proibidos de exercer nossa autonomia.

\section{Indivíduos maduros e tempos difíceis}

Começamos com a ideia de subjetividade para compreender o surgimento do Racionalismo. Daí, derivam-se diversos caminhos de formação até o contexto atual e, portanto, seguiremos daí para entender como sujeitos maduros em sua subjetividade podem reagir diante de situações estressoras.

A tendência de algumas pessoas a entregarem sua liberdade e autonomia nas mãos do governo, deixando sobre o Estado a responsabilidade por sua segurança e proteção, considerando que ele sabe o que é melhor do que o próprio indivíduo, pode levar a sociedade a lugares perigosos. Talvez isso acontece como uma tentativa de garantia de segurança. Como já citada, na política da fé, os poderes do Estado são expandidos, e não limitados e, ironicamente, entender as soluções políticas como verdades inquestionáveis mina a capacidade de raciocinar das pessoas. 
Winnicott (1999), psicanalista inglês e estudioso do amadurecimento humano, defende que um indivíduo maduro tem sua vida marcada por características positivas e negativas, o que inclui medos, dúvidas e frustrações. Para ele, o indivíduo saudável entende que é impossível evitar as circunstâncias ruins, o que vai contra a ideia de uma tentativa de garantir situações com menos riscos e mais seguranças através de soluções políticas.

$\mathrm{O}$ indivíduo que atingiu o amadurecimento não terceiriza responsabilidades, não se vitimiza, e muito menos elege um representante ou uma causa ideológica para justificar suas ideias. Isto é, não é necessário para ele depositar suas esperanças em um ente abstrato governamental ou tratar o Estado como um pai que precisa protegê-lo de si mesmo a todo custo. É característica marcante justamente de um indivíduo imaturo aderir a uma ideia abstrata de poder ou segurança, na tentativa de aliviar seus conflitos, sejam internos ou externos já que ele não suporta a realidade de si-mesmo e do mundo, sendo ambas distorcidas (WINNICOTT, 1999, p. 249-271).

O sujeito maduro e saudável é capaz de avaliar objetivamente a realidade, justamente porque reconhece os limites entre o eu e o não-eu, entre o real compartilhado e os fenômenos de sua própria subjetividade. Winnicott vai além e afirma que é marca do amadurecimento que a pessoa seja ativo em sua comunidade de maneira prática, exercendo seu papel criativo no cuidado consigo próprio e com os outros ao seu redor. Esta pessoa amadurecida, em uma pandemia, não vai tentar se descolar da realidade, aderindo a princípios abstratos auto completos. Ao contrário, tendo seus valores como norteadores, buscará maneiras responsáveis de agir no mundo e de vivenciar suas relações interpessoais.

Winnicott também apresenta a possibilidade de que a democracia seja estudada a partir do ponto de vista psicológico. Nesse sentido, os ambientes sociais saudáveis são justamente marcados pela presença de indivíduos maduros, que exercem um cuidado responsável. Um conceito winnicottiano essencial aqui é o de "cuidados maternos suficientemente bons", fundamentais para o amadurecimento humano e cujas principais características são a estabilidade, a previsibilidade e a adaptação às necessidades do sujeito. Esses cuidados, posteriormente, são cumpridos por outros familiares e grupos sociais.

O processo de amadurecimento oriundo daí resulta em uma sociedade sadia, que não impede que seus cidadãos façam escolhas pessoais, pensando livremente e atuando com liberdade em diversos âmbitos de sua vida, o que mantém a estabilidade da máquina democrática. Então, em termos winnicottianos, a responsabilidade de contribuir com a sociedade fundamenta a liberdade das pessoas em uma sociedade madura e o bom funcionamento da sociedade avança conforme o desenvolvimento pessoal de seus membros, envolvendo questões relacionadas a maturidade, incluindo o desenvolvimento moral, que é baseado no cuidado ambiental para com as necessidades.

Entretanto, o que vemos vai na contramão disso. Furedi (2020), escritor e professor de sociologia de uma universidade do Reino Unido, afirma que a linguagem pública atual vem sofrendo uma perda intencional de visão da realidade. Com isso, os significados clássicos das palavras têm se esvaziado, impedindo que as questões sociais sejam discutidas a partir de um ponto de referência comum na realidade objetiva, gerando discussões vazias, permeadas de 
questões ideológicas abstratas. Consequência? Indivíduos imaturos, considerando que para Winnicott, maturidade também está relacionada com a tolerância a opiniões opostas, envolvendo debates acalorados e, talvez, desgastantes, mas necessários para o bom funcionamento social.

Em um contexto de crise, é provável que essas dificuldades se intensifiquem. Através dessa perspectiva mais coletiva, Furedi aponta que a maneira como uma comunidade reage a um perigo está diretamente associada com a percepção que existe sobre essa ameaça e a capacidade de dar sentido a ela. É como se as questões culturais comunicassem regras subjacentes sobre como um povo deve reagir diante de uma ameaça, influencia a noção das pessoas sobre sua própria vulnerabilidade. Ou seja, se em um contexto preexistente, as pessoas já sentiam dependência em relação ao Estado, isso será intensificado em uma situação de crise.

Se levarmos em consideração a experiência humana acumulada ao longo da história, percebemos logo que sujeitos livres, desde muito tempo atrás, respondem a desafios das melhores formas que encontram. Em períodos difíceis, as pessoas não ficam simplesmente imóveis. Ainda que pareçam retrógradas, virtudes como a coragem, o altruísmo, a benevolência e a responsabilidade formaram a capacidade humana, ao longo dos séculos, de utilizar recursos para reagir a desastres e situações de crise. Não fosse assim, não teríamos sobrevivido até aqui.

Oincentivo da infantilização eterna de jovens e adultos que depositam suas responsabilidades fora de si e a ideia de vulnerabilidade sendo aplaudida reduz a capacidade da humanidade de sobreviver diante das intempéries e de resistir às adversidades, muitas vezes inerentes à existência humana. Isso produz para nós uma sociedade incapaz de amadurecer, que continuará, constantemente, concedendo mais e mais poderes ao Estado.

Considerando os princípios do amadurecimento humano a partir de uma perspectiva psicológica e os princípios norteadores de uma política instalada na realidade, nada é melhor do que permitir que indivíduos adultos respondam por si mesmos, incentivando-se de maneira mútua a agir de maneiras responsáveis e maduras. Por que não permitir que as pessoas que vivenciam problemas concretos lidem com suas próprias situações concretas? Por que retirar a liberdade ao indivíduo humano e entregá-la a um grupo que supostamente sabe o que é melhor para todos?

A pandemia e todo o contexto caótico de 2020 nos traz grandes desafios e em diversos níveis. Precisamos aprender a real importância das experiências práticas acumuladas ao longo da história humana, nos instalando na realidade concreta e aprendendo a observá-la objetivamente. Precisamos amadurecer enquanto sociedade, entendendo que nossas responsabilidades como indivíduos não podem ser terceirizadas, por mais bem intencionado que o Estado alegue estar. E precisamos também entender o papel desse Estado, justamente para não cairmos em horizontes abstratos e inalcançáveis, o que remete à conhecida metáfora usada por Oakeshott:

Aquele que tem a habilidade de manter o navio em estado de equilíbrio. [...] Procura moderar o conflito, pois a necessidade de mudança pode ser admitida sem o estímulo de expectativas ilusórias. [...] Está preocupado em evitar que a política rume aos extremos [...]. Poderá ser visto lidando em qualquer direção que a ocasião exija para que o barco possa prosseguir (OAKESHOTT, 2018, p. 22). 


\section{Referências}

BAPTISTA, Ligia Pavan. Guerra e paz na teoria política de Thomas Hobbes. In: $3^{\circ}$ ENCONTRO NACIONAL ABRI 2011. Associação Brasileira de Relações Internacionais Instituto de Relações Internacionais - USP. Proceedings online, São Paulo, v. 3, 2011.

CLAUSEWITZ, Carl Von. Da Guerra. São Paulo: Editora WMF Martins Fontes, 2010.

FIGUEIREDO, Luis Cláudio. Psicologia. Uma (nova) introdução. São Paulo, Abril Cultural, 1979.

FUREDI, Frank. Are we allowed to call them riots? Spiked online, 2020. Disponível em: https://www.spikedonline.com/2020/06/02/are-we-allowed-to-call-them-riots//. Acesso em: 5 jul 2020.

HOBBES, Thomas. Leviathan. London, Penguin Classics, 1979.

OAKESHOTT, Michael. A política da fé e a política do ceticismo. São Paulo: É realizações, 2018.

OAKESHOTT, Michael. Rationalism in politics. London: Liberty Fund, 1962.

PONTES, José Nailton Rocha. Do absolutismo de Hobbes ao liberalismo de Locke: do estado natureza ao estado civil. Jus Online, 2017. Disponível em: https://jus.com.br/artigos/55942/do-absolutismo-de-hobbes-ao-liberalismode-locke-do-estado-natureza-ao-estado-civil. Acesso em: 27 jun 2020.

ROTHBARD, Murray. A anatomia do Estado. Tradução de Matheus Pacini. Campinas: Vide Editorial, 2019.

SOUZA, Josias de. Lula: 'Ainda bem que a natureza criou o coronavírus. UOL, 2020. Disponível em: https:// noticias.uol.com.br/colunas/josias-de-souza/2020/05/20/lula-ainda-bem-que-a-natureza-criou-o-coronavirus. htm. Acessado em: 05 jul 2020.

TORRES, Marcos Abreu. Ao contrário do que diz Lula, não é necessária uma pandemia para as pessoas se lembrarem do estado. Mises Brasil, 2020. Disponível em https:/www.mises.org.br/article/3253/ao-contrario-doque-diz-lula-nao-e-necessaria-uma-pandemia-para-as-pessoas-se-lembrarem-do-estado. Acessado em: 5 jul 2020.

WINNICOTT, D. W. Tudo começa em casa. São Paulo: Martins Fontes, 1999.

RECEBIDO: 5 DE AGOSTO 2020

APROVADO: 14 DE SETEMBRO 2020 